\title{
IMPLEMENTATION OF STATISTICAL QUALITY CONTROL (S.Q.C.) IN WELDED STAINLESS STEEL PIPE MANUFACTURING INDUSTRY
}

\author{
Kapil Banker', Amit Patel ${ }^{2}$, Diptesh Patel ${ }^{3}$ \\ ${ }^{1}$ Assistant Professor, Mechanical Department, Shankersinh Vaghela Bapu Institute of Technology, Gujarat, India \\ ${ }^{2}$ Assistant Professor, Mechanical Department, Shankersinh Vaghela Bapu Institute of Technology, Gujarat, India \\ ${ }^{3}$ Assistant Professor, Mechanical Department, Shankersinh Vaghela Bapu Institute of Technology, Gujarat, India
}

\begin{abstract}
Stainless steel welded pipe is manufacture by various methods like as shearing, bending, partial welding, full welding, nitriding, final length, expanding and buffing. This research is about to implement statistical quality control tools in pipe manufacturing industries. There are various defect found in stainless steel welded pipe manufacturing, due to these defects, pipes are rejected lot wise, and that is very unproductive result for each and every industries. Statistical quality control (SQC) tools, such as $x$ bar chart, $R$-chart, $C$-chart, P-chart had been utilized to measure the variability in the process. We observed good result about the process, whether it is in control or not. These types of charts will also provide the fast result that will be used to take action immediately.
\end{abstract}

In pipe manufacturing industries, rejection reduction is possible by proper shearing process, appropriate welding line, maintaining expanding process. This research helps to decide the process within the control limit or not, that would be decided by various control charts. This is also used for quality improvement. In S.Q.C, there are number of tools used such as Frequency distribution, Control charts, acceptance sampling, and analysis of the data. From all of these tools, we have to concentrate only on control charts. Ultimately, It has been used for any manufacturer to solve the rejection problem, enhancing the productivity and quality of the product.

In apurvi industries, out of control process has been detected by Xbar and $R$ chart and root cause analysis used for defect detection. $C$ chart has also been used for depicted the number of defects in the particular lot. Using the C chart it can be easily decided whether the particular lots are accepted or not. Flow of this research is the beginning with the introduction, Literature review regarding the research area then Methodology followed by the result and discussion. Finally future scope of the research is presented.

Keywords: Statistical Quality Control, S.Q.C, Stainless Steel Pipe industry, Rejection Reduction, Manufacturing Industry.

\section{INTRODUCTION}

Basically, there are two types of stainless steel welded pipe.

1. Seamless pipe and

2. Welded pipe.

Stainless steel welded pipes are used in production of submersible pump as a part. Other application of stainless steel welded pipe for pumps, furniture etc. It is made of stainless steel metal such as $202,302,4 \%$ and many more types of stainless steel. Mostly stainless steel welded pipes are used as a body part of submersible pump. It is available in various diameter and length as per the customer's requirement. It has been used for assembling purpose of the submersible pump so extra care must be taken during production of stainless steel pipe. Every manufacturer of stainless steel welded pipe wants the best quality of the product. Due to this they gave concentrate on the good quality of the pipe through defect reduction. In pipe manufacturing, there are various defect found such as ovality in diameter, porosity in weld line, peak and valley on cylindrical surfaces, variation in thickness on weld line, porosity in pipe etc., Stainless steel pipes are made by the number of process, such as shearing process, bending, partial welding, full welding, nitriding, expanding, final length and last one is buffing or polishing. Shearing process involves sheet cutting into require size on the shearing machine.

\subsection{Objective of Research}

The objective of this research is:

1. Cost reduction of stainless steel welded pipe.

2. Improve quality of stainless steel welded pipe.

3. Productivity improvement through S.Q.C tools.

4. Rejection reduction of the product.

\subsection{Scope of the Research}

The scope of the research is to overcome defects through the statistical quality control method. The main concentration of this research is to overcome ovality problem. These results can be used for seamless pipe also 


\section{LITERATURE REVIEW}

In "MACHINE TOOL CONDITION MONITORING USING STATISTICAL QUALITY CONTROL CHARTS by A. D. JENNINGS and P. R. DRAKE" have focused on the application of control chart to monitoring the machine tool performance parameters. They developed the effective maintenance system by setting arbitrarily alarm with the control limits. When the process being out of control the alarm automatically rung and operator can understand there are some problem in machine.

They used V4-6 CNC vertical milling machine for recording various data. They also developed control chart for diagnosis the problem of machine tool parameter. While the determination of problem for machine maintenance, they focused on one, two and three variable for depicted the control chart. Ultimately they conceded that the control charts have been introduced for monitoring of machine tool parameter.

In "Statistical process control in machining, a case study for machine tool capability and process capability" by Ali Riza Motorcu, Abdulkadir. They focused on statistical process control method to eliminate the quality problems such as undesirable tolerance limits, circularity of spheroidal cast iron parts during machining. At the stage of study they observed that some parts were oval and out of tolerance limit, machines and processes were insufficient and production was instable. The data had been gathered and through the analysis of data some assignable cause for faulty work pieces were discovered. In addition to these developments, surface roughness and circularity of work pieces were improved.

They concluded that, the production had not carried on normally before the statistical work. After the statistical study, during the machining the sizes having quality problems the production lines where parts were manufactured out of tolerance were determined. It was detected that the machine tool and process capability for the whole process was inadequate and the mass production was unstable. Ovality, faults regarding manufacturing out of tolerance limits were eliminated and surface roughness was improved.

As a result of their study, the employee understood the quality requirement, the cost due to inequality production was reduced and the production was enabled to carry on normally with the help of problem solving desire of them. Since this study reduced the inequality costs during production, the company management supported the study. However, because of economic problems

In "Quality estimation of process with usage control charts type X-R and quality capability of process Cp, Cpk" by M. Dudek-Burlikowska has focused on statistical quality control method to resolve the problem of process capability. He used the X-R chart for process capabilities and concluded that Usage of quality research and estimation methods in Polish industry permits to avoid occurrences of productive defects already in production stage, which helps in elimination of their source formation. The most popular method used in quality assurance systems for productive process is statistical process control. SPC involves using statistical techniques to measure and analyze the variation of the process. Most often used for manufacturing processes, the intent of SPC is to monitor product quality and maintain processes to a fixed target.

He concluded that the aim of usage of control charts type X$\mathrm{R}$ in above process was to measure and minimize the variations that occurs in the process, and the essential aspect was delimitation of coefficients of process correctness that leads to improvement. He was also found that from the investigational processes that usage of quality statistic methods was a good factor which permits to qualify, when emerging problems can be solved locally, and when the collective decision of the management is necessary.

In "statistical process control for the process industries" by John A. Shaw has focused on statistical quality control chart. He observed that process is out of control when $\mathrm{X}$ bar values reached beyond control limits. He also observed that an important part of the $\mathrm{X}$ chart is the sub grouping of four to five measurements that are averaged to provide one point on the chart. The concept is that the natural inherent variation will be reflected in the average range of the subgroup, while the difference between one subgroup and another will; if it is greater than a certain amount, and reflect the assignable cause. He was also introduced a alarm system for process industries. As per his observation one application of SPC is to produce alarms when the measured variable is out of statistical control. He concluded that Statistical process control has served as an important tool in the discrete parts manufacturing industries to improve product quality, reduce variability, and decrease cost. It is being adopted by many companies in the chemical process industries, in part due to pressure from their customers. In some areas within the chemical industry, SPC has proven to be a useful and successful tool. Its applicability must be examined in all areas of the chemical industry, application by application. Two primary considerations should govern its acceptance for each individual application: the ability of SPC to produce meaningful results, and the need for SPC as compared to other statistical and non statistical tools.

\section{METHODOLOGY}

Implementation of Statistical Quality control in Stainless Steel Welded pipe manufacturing industry with the association of control charts. In this research paper we adopted the control chart method to observe and control the process along the manufacturing process line. $\mathrm{X}$ bar char, $\mathrm{R}$ chart has been suggested for this research and according to the control chart, result and discussion is presented.

\section{RESULTS AND DISCUSSION}

Test Results For Ksb Pump Pipe:-KSB pump is a well known company in manufacturing of submersible pump. They have been made various size of pump within the pump 
body tolerance $0.10 \mathrm{~mm}$. KSB pump is Apurvi industries costumer so, different pump pipe has been made by Apurvi industries within the tolerance limit $0.10 \mathrm{~mm}$. Result of KSB pump pipe as per the given specification is as follows.

Diameter of pipe:- $81.20 \mathrm{~mm}(0.10)$

Sample size :- 25 nos.

Observations :- 04 nos.

Below mentioned test results are used for depicted the X-bar and $\mathrm{R}$ chart, which will decided whether the process is in control or out of controlled. The X-bar and $\mathrm{R}$ chart for the below test result is as mentioned in the above figure.

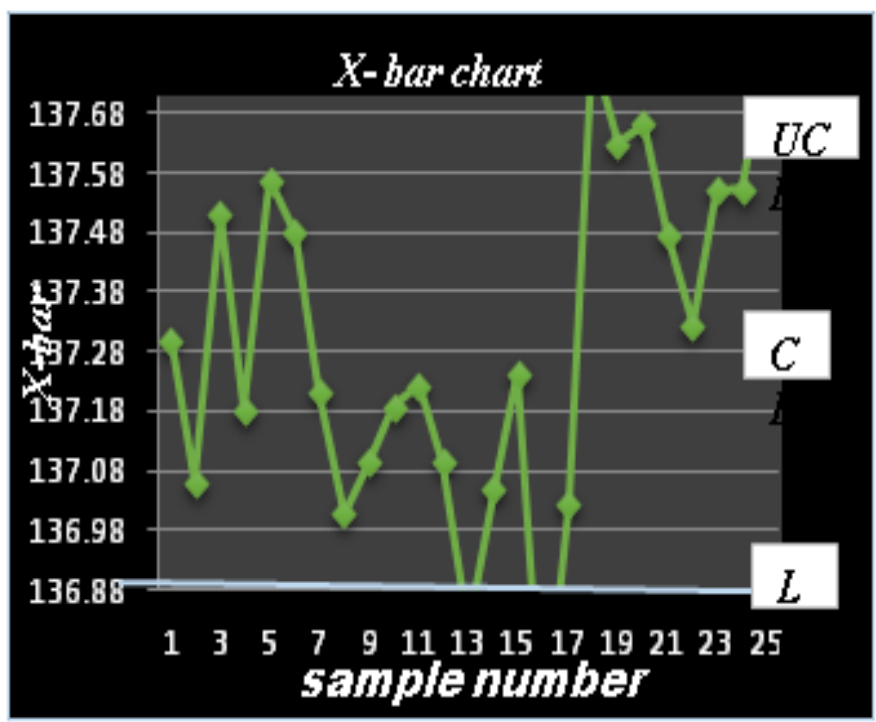

Fig $1 \mathrm{X}$ bar Chart

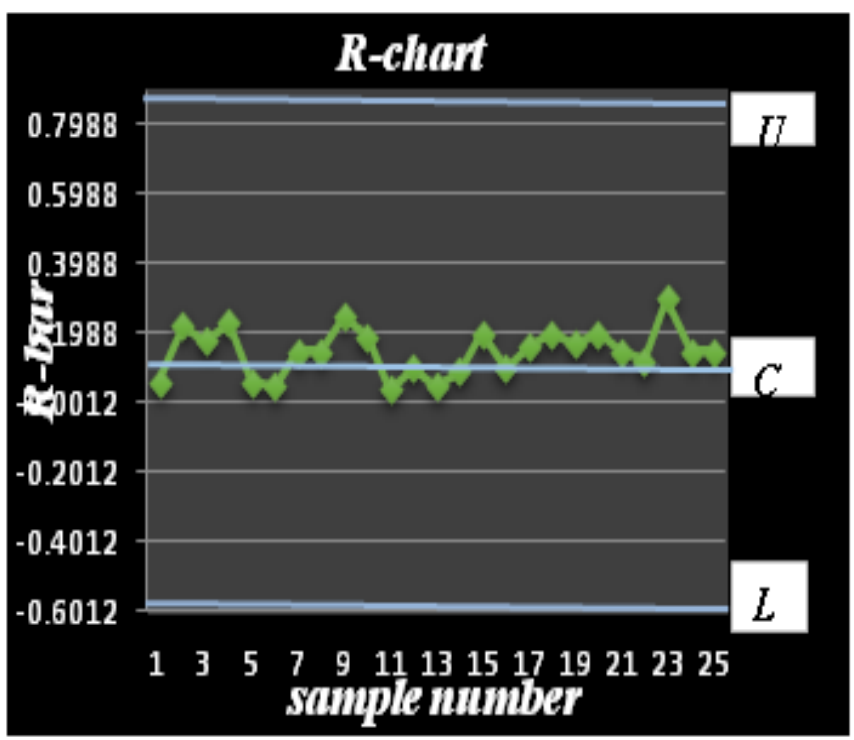

Fig 2 R Chart
Table: 1 Test Result Table

\begin{tabular}{|c|c|c|c|c|c|c|}
\hline $\begin{array}{l}\text { Sample } \\
\text { no. }\end{array}$ & 1 & 2 & 3 & 4 & $\begin{array}{l}\mathrm{X} \text { - } \\
\text { average }\end{array}$ & Range \\
\hline 1 & 81.1 & 81.1 & $\begin{array}{l}81.1 \\
5\end{array}$ & $\begin{array}{l}81.1 \\
6\end{array}$ & 81.1275 & 0.06 \\
\hline 2 & $\begin{array}{l}81.1 \\
4 \\
\end{array}$ & $\begin{array}{l}81.1 \\
2 \\
\end{array}$ & $\begin{array}{l}81.3 \\
4 \\
\end{array}$ & $\begin{array}{l}81.2 \\
3\end{array}$ & 81.2075 & 0.22 \\
\hline 3 & $\begin{array}{l}81.1 \\
3\end{array}$ & $\begin{array}{l}81.1 \\
6\end{array}$ & $\begin{array}{l}81.1 \\
8\end{array}$ & 81 & 81.1175 & 0.18 \\
\hline 4 & 81.3 & $\begin{array}{l}81.3 \\
3\end{array}$ & $\begin{array}{l}81.2 \\
5\end{array}$ & 81.1 & 81.245 & 0.23 \\
\hline 5 & $\begin{array}{l}81.1 \\
5 \\
\end{array}$ & $\begin{array}{l}81.1 \\
6 \\
\end{array}$ & $\begin{array}{l}81.1 \\
5 \\
\end{array}$ & 81.1 & 81.14 & 0.06 \\
\hline 6 & 81.2 & 81.2 & $\begin{array}{l}81.2 \\
5\end{array}$ & 81.2 & 81.2125 & 0.05 \\
\hline 7 & $\begin{array}{l}81.2 \\
7 \\
\end{array}$ & $\begin{array}{l}81.2 \\
5 \\
\end{array}$ & $\begin{array}{l}81.1 \\
5\end{array}$ & 81.3 & 81.2425 & 0.15 \\
\hline 8 & $\begin{array}{l}81.1 \\
5\end{array}$ & 81.1 & $\begin{array}{l}81.1 \\
5\end{array}$ & $\begin{array}{l}81.2 \\
5\end{array}$ & 81.1625 & 0.15 \\
\hline 9 & $\begin{array}{l}81.1 \\
5\end{array}$ & 81.3 & $\begin{array}{l}81.3 \\
5\end{array}$ & 81.1 & 81.225 & 0.25 \\
\hline 10 & 81.1 & $\begin{array}{l}81.1 \\
2 \\
\end{array}$ & $\begin{array}{l}81.1 \\
5 \\
\end{array}$ & $\begin{array}{l}81.2 \\
9 \\
\end{array}$ & 81.165 & 0.19 \\
\hline 11 & 81.2 & $\begin{array}{l}81.2 \\
4 \\
\end{array}$ & $\begin{array}{l}81.2 \\
3 \\
\end{array}$ & $\begin{array}{l}81.2 \\
4 \\
\end{array}$ & 81.2275 & 0.04 \\
\hline 12 & 81.2 & $\begin{array}{l}81.2 \\
2 \\
\end{array}$ & $\begin{array}{l}81.2 \\
5 \\
\end{array}$ & $\begin{array}{l}81.1 \\
5 \\
\end{array}$ & 81.205 & 0.1 \\
\hline 13 & 81.1 & 81.1 & $\begin{array}{l}81.1 \\
5 \\
\end{array}$ & $\begin{array}{l}81.1 \\
4 \\
\end{array}$ & 81.1225 & 0.05 \\
\hline 14 & 81.1 & 81.1 & $\begin{array}{l}81.1 \\
5 \\
\end{array}$ & $\begin{array}{l}81.1 \\
9 \\
\end{array}$ & 81.135 & 0.09 \\
\hline 15 & 81.1 & 81.3 & 81.2 & 81.2 & 81.2 & 0.2 \\
\hline 16 & 81.2 & 81.3 & $\begin{array}{l}81.2 \\
6\end{array}$ & $\begin{array}{l}81.2 \\
3\end{array}$ & 81.2475 & 0.1 \\
\hline 17 & 81.1 & $\begin{array}{l}81.2 \\
6 \\
\end{array}$ & $\begin{array}{l}81.1 \\
5\end{array}$ & $\begin{array}{l}81.1 \\
4 \\
\end{array}$ & 81.1625 & 0.16 \\
\hline 18 & 81.1 & $\begin{array}{l}81.1 \\
5 \\
\end{array}$ & 81.3 & 81.3 & 81.2125 & 0.2 \\
\hline 19 & $\begin{array}{l}81.2 \\
7 \\
\end{array}$ & $\begin{array}{l}81.2 \\
5 \\
\end{array}$ & 81.2 & 81.1 & 81.205 & 0.17 \\
\hline 20 & 81.1 & $\begin{array}{l}81.1 \\
5 \\
\end{array}$ & $\begin{array}{l}81.1 \\
4 \\
\end{array}$ & 81.3 & 81.1725 & 0.2 \\
\hline 21 & 81.1 & $\begin{array}{l}81.1 \\
7 \\
\end{array}$ & 81.2 & $\begin{array}{l}81.2 \\
5 \\
\end{array}$ & 81.18 & 0.15 \\
\hline 22 & 81.1 & 81.2 & 81.2 & $\begin{array}{l}81.2 \\
2 \\
\end{array}$ & 81.18 & 0.12 \\
\hline 23 & 81 & 81.1 & 81.3 & 81.1 & 81.125 & 0.3 \\
\hline 24 & 81.1 & $\begin{array}{l}81.1 \\
5\end{array}$ & $\begin{array}{l}81.2 \\
5\end{array}$ & $\begin{array}{l}81.1 \\
5\end{array}$ & 81.1625 & 0.15 \\
\hline \multirow[t]{3}{*}{25} & 81.1 & $\begin{array}{l}81.2 \\
5 \\
\end{array}$ & 81.1 & $\begin{array}{l}81.1 \\
5 \\
\end{array}$ & 81.15 & 0.15 \\
\hline & & & & & 81.1813 & 0.1488 \\
\hline & & & & & Xbar-bar & R-bar \\
\hline
\end{tabular}


Here, in KSB pump pipe the diameter of pipe is 81.20 and $0.10 \mathrm{~mm}$ tolerance. As per the result table, value of X-bar is $81.18 \mathrm{~mm}$. that is within the specifications. Most of the diameter values under the upper and lower specification limits. The X-bar and $\mathrm{R}$ chart result gives the clear idea that the process within the control limits.

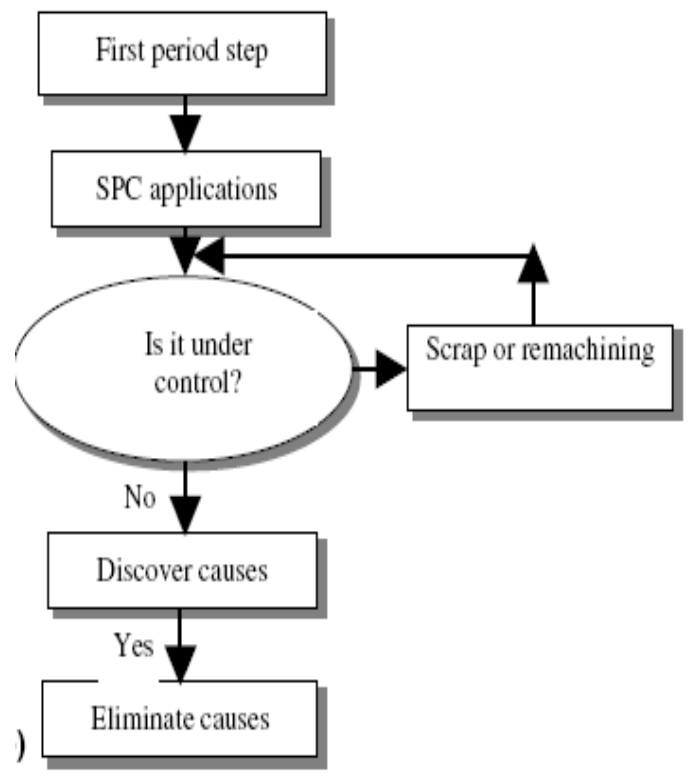

Fig.3 Conceptual Model Of SPC

\section{CONCLUSIONS}

It is observed that in $\mathrm{X}$ bar and $\mathrm{R}$ chart, if the process is out of control, then some assignable causes are there. In aputrvi industries, there was no provision for detected and eliminated any assignable causes from the process. That was the main disadvantage in the company to increased overhead cost due to trial and error method to solve the problem.

Any manufacturing unit or industries must have to eliminate assignable causes for flexible production. Defects had been enhanced by assignable causes and ultimately productivity had diminished day by day till the elimination of assignable causes. Through the root causes analysis assignable causes are detected and it had been eliminated by readjusting the machines, proper work distribution and introducing control charts.

In Apurvi industries the main defect observed was ovality in stainless welded pipe. The ovality defect has been eliminated by adjusting the expanding pressure in the expanding machine. Expanding machine has been used for maintaining circularity of the pipe. If the pressure of machine is exceeded than ovality defect is developed in the pipe. The control charts are used for online inspection process in the industries. Online defect detection has been occurred by control charts.

Productivity has been increased in Apurvi industries by applying statistical quality control. It is clearly observed in the conceptual model of statistical process control, that productivity has been increased after implementing the statistical quality control in Apurvi industries.

\section{REFERENCES}

[1] Himmelblau, David M, Porcess Analysis by Statistical methods, Wiley 1970

[2] A.D. Jennings, P.R Drake, Machine tool condition Monitoring using Statistical Quality Control Charts. November 1996.

[3] Ali Riza Motorcu, Abdulkadir Gullu, "Statistical process control in machining, A case study for machine tool capability and process capability" December 2014.

[4] M. Dudek, Burlikowska, "Quality estimation of process with usage control charts type $\mathrm{X}-\mathrm{R}$ and quality capability of processes $\mathrm{C}_{\mathrm{P}} \& \mathrm{C}_{\mathrm{PK}}$.

[5] Jenn-Hwai Yang, Miin-Shen Yang, “ A control chart pattern recognition system using statistical correlation coefficient method" 2005.

[6] Charles J. Corbett,"Evaluating environmental performance using process control techniques" 2002.

\section{BIOGRAPHIES}

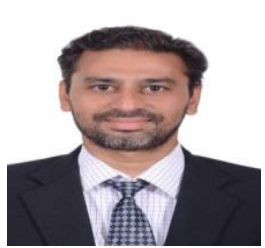

K.S. Banker received the B.E and M.E Degrees in Mechanical Engineering from Government Engineering College, Bhuj in 2001, and M.S. University, Baroda in 2011 respectively.

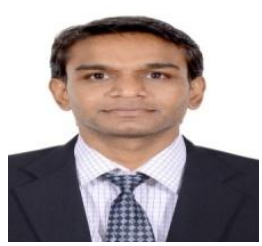

Diptesh Patel received the B.E. and M.E. Degree in mechanical Engineering from Nasik and Australia respectively. $\mathrm{He}$ is doing his Ph.D. Degree from Gujarat, India.

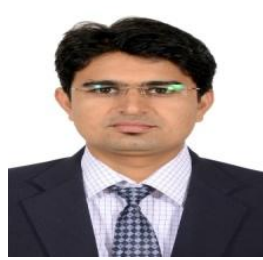

Amit Patel received the B.E. and M.E. Degree in mechanical Engineering from Gujarat, India. 